\title{
Double Aneuploidy: 48,XXY,+18 in a Bedouin Boy
}

\author{
S.A. Al-Awadi a R.L. Al-Naggara S.M. Tayel ${ }^{a}$ R. Uma ${ }^{b}$ \\ aKuwait Medical Genetics Center, Maternity Hospital, and 'Pediatric Department, \\ Al-Jahra Hospital, Kuwait
}

\section{Key Words}

Double aneuploidy . Trisomy 18 .

Klinefelter's syndrome

\begin{abstract}
Objective: This study describes a case of double aneuploidy $(48, X X Y,+18)$, makes genotype-phenotype correlation of the case and compares it with those in the literature. This study throws more light on the origin of double aneuploidy. Methods: Clinical examination, skeletal survey, echocardiography, cranial ultrasonography and chromosomal examination of a peripheral blood sample using GTG-type of banding were performed. Results: Clinical examination of the 25-dayold boy showed craniofacial dysmorphic features suggestive of trisomy 18, ventricular septal defect and complicated postnatal events leading to his neonatal death. Skeletal survey demonstrated absence of ossification centers of the epiphyses of long bones. Cranial ultrasonography revealed bilateral ven-
\end{abstract}

\begin{tabular}{ll}
\hline KARGER & (1) 1999 S. Karger AG, Basel \\
Fax +41 61 306 1234 34 & \\
$\begin{array}{l}\text { E-Mail karger@karger.ch } \\
\text { www.karger.com }\end{array}$ & $\begin{array}{l}\text { Accessible online at: } \\
\text { http://BioMedNet.com/karger }\end{array}$
\end{tabular}

triculomegaly with thin cerebral cortex. Chromosomal analysis showed $48, X X Y,+18$ karyotype with no evidence of mosaicism. Conclusion: In the very few reported cases of double aneuploidy involving autosomes and sex chromosomes the clinical manifestations of the sex chromosome abnormality are usually missing. Double aneuploidy reflects a more serious segregation defect of meiosis than simple nondisjunction, and is not simply the result of the rare coincidence of paternal and maternal nondisjunction.

\section{Introduction}

Double aneuploidy is very rare. The frequency of conceptions with double aneuploidy (e.g. 48,XXY,+21; 48,XXY,+18; $48, \mathrm{XXX},+21)$ may be higher than that predicted by the frequency of the individual aneuploidies alone [1]. Trisomy 18 is the second most common autosomal trisomy at

Dr. R.L. Al-Naggar

Kuwait Medical Genetics Center

Maternity Hospital, PO Box 31121

Sulaibikhat 80901 (Kuwait)

Tel. +965 481 4328, Fax +965 4842073 


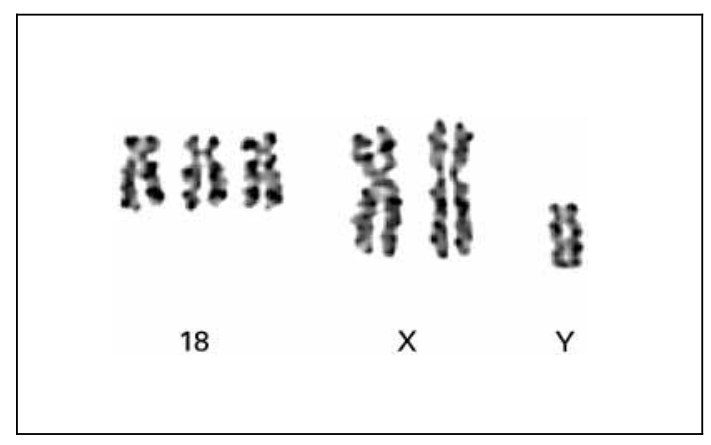

Fig. 1. Partial karyotype (GTG banding) of the 48,XXY,+18 patient.

birth, having a newborn frequency of $1 / 8,000$ [2]. Trisomy 18 and most other trisomies demonstrate a strong association with increased maternal age [3]. The additional chromosome is maternal in more than $90 \%$ of occurrences of trisomy 18 and in about half of the cases of XXY [4, 5]. Klinefelter syndrome $(47, \mathrm{XXY})$ is the most common cause of hypogonadism in males. The newborn incidence is about 1 in 600 males [6]. The fetal survival rate is reported to be $97 \%$. The newborn with $47, \mathrm{XXY}$ has no significant dysmorphism. However, there is some evidence of a slight increase in neonatal deaths. Minor congenital abnormalities, particularly clinodactyly, occur in about $25 \%$ of them [7]. Prepubertal boys with $47, \mathrm{XXY}$ appear normal, and it is unusual for the diagnosis to be made by pediatricians. The majority of those who are identified are adults with tall stature, small testes, infertile, and having an increased risk for developmental problems.

\section{Case Report}

The propositus was the 3 rd delivery after 2 normal children and a spontaneous abortion. The pregnancy was uneventful except for an intrauterine growth deficiency noted upon delivery. He had low Apgar scores and a complicated postnatal course. The consanguineous Bedouin parents were healthy, and their ages were 29 years for the mother and 31 years for the father at the time of the $3 \mathrm{rd}$ baby. The birth weight was $1.3 \mathrm{~kg}$, and cyanosis with respiratory distress and apnea were apparent shortly after birth. He needed resuscitation and incubator care. Clinical examination showed microcephaly (occipitofrontal distance $=31 \mathrm{~cm} ;<5$ th centile), protruding occiput, triangular face, hypertelorism, depressed nasal bridge, small mouth, microretrognathism, high-arched palate, wide-spaced nipples, clinodactyly of the 5th fingers, bilateral valgus deformity, micropenis, undescended testicles, and systolic murmur over the left 3rd and 4th intercostal spaces. Skeletal survey revealed absence of ossification centers of the epiphyses of long bones, thin 12 pairs of ribs and cardiomegaly. Echocardiography demonstrated the presence of a large ventricular septal defect. Cranial ultrasonography showed bilateral ventriculomegaly with thin cerebral cortex. The blood indices revealed leukopenia $\left(\mathrm{WBCs}=5,700 / \mathrm{mm}^{3}\right)$, thrombocytopenia (platelets $\left.=15,000 / \mathrm{mm}^{3}\right)$, low hemoglobin level $(9.5 \mathrm{~g} /$ $\mathrm{dl}$ ), and high serum bilirubin (244 mmol/l). Chromosomal analysis of a peripheral blood sample using Giemsa trypsin (GTG banding) showed the karyotype of $48, \mathrm{XXY},+18$ with no evidence of mosaicism in 50 metaphase spreads (fig. 1).

\section{Discussion}

Very few cases of double aneuploidy involving chromosome 18 and sex chromosomes are reported [8-14]. The present case of $48, \mathrm{XXX},+18$ is the second case of double aneuploidy among 6,906 cases karyotyped in Kuwait during the past 10 years (1988-1997). The first case was $48, \mathrm{XXY},+18$ with multiple congenital anomalies suggestive of trisomy 18 and who died few hours after birth. The boy of the present study also presented with features of trisomy 18. In all the cases of double aneuploidy involving autosomes and sex chromosomes cited in the literature [8-14], the clinical manifestations of the sex chromosomal abnormality are usually missing obviously because some sex chromosome abnormalities as triple $\mathrm{X}$ and XXY do not have any character- 
istic clinical features, and others such as XXY might not manifest themselves until puberty.

The parental origin of the additional chromosome in trisomy 18 is maternal in origin in the majority $(96.8 \%)$ of cases [4]. Trisomy 18 differs from trisomy 21, XXX and XXY of maternal origin by the preponderance of meiosis II versus meiosis I (MI) nondisjunction $[4,15]$. The frequency of maternal MI nondisjunction appears to be similar for chromosomes 18 and $\mathrm{X}$, but the mechanisms are somewhat different. In both chromosomes, nullichiasmate (chiasmata are the discrete points of contact between the chromatids of the homologous chromosomes in the prophase of MI and they are the sites of crossing over or chromatid exchange) nondisjunction accounts for $30 \%$ of all maternal MI errors, but in chromosome 18 the remaining maternal MI errors all appear to be normochiasmate and related to increased maternal age. In $\mathrm{X}$ chromosome nondisjunction only about $45 \%$ are normochiasmate, and the remaining $25 \%$ is associated with an excess of pericentromeric recombination that is not related to increased maternal age. Chromosome length is directly related to the frequency of chiasma formation with reduced frequency in shorter chromosomes. At least one chiasma (obligate chiasma) is necessary for normal first anaphase segregation because chiasma formation ensures the correct orientation of the two homologues within the metaphase plate. Therefore lack of chiasma formation can give rise to nondisjunction by random segregation [16]. The maternal age effect leading to nondisjunction is explained by its association with chromosome laxity secondary to impairment of appropriate chromosome coiling and condensation in the oocytes of old women [16]. Parental consanguinity may also increase the risk of trisomy in the offspring through the postulation of the presence of an autosomal recessive gene causing nondisjunction [17].

Opposite to trisomy 18, approximately half of 47,XXY individuals have both X and $\mathrm{Y}$ inherited from the father, suggesting that the XY bivalent is particularly susceptible to nondisjunction and marked reduction in combination [18].

DNA polymorphisms have been used to investigate parental origins of both aneuploid chromosomes in 3 cases of spontaneous abortion and in each case, both nondisjunctions occurred in a single parent [19]. The parental origin of the extra two chromosomes in the present case could not be determined using polymorphic DNA markers due to an early death of the patient.

Nondisjunction in both gametes could lead to the formation of double aneuploidy zygote. Alternatively, a single global defect might cause multiple nondisjunctions in a single gamete [20]. Therefore, double nondisjunction is not simply the result of the rare coincidence of paternal and maternal nondisjunction. 


\section{References}

1 Ikonen RS, Lindlof M, Janas MO, Simola KO, Millington-Ward A, de la Chapelle A: Coincident maternal meiotic nondisjunction of chromosomes $\mathrm{X}$ and 21 without evidence of autosomal asynapsis. Hum Genet 1989;83:235-238.

2 Hook EB, Hamerton JL: The frequency of chromosome abnormalities detected in consecutive newborn studies: Differences between studies results by sex and by severity of phenotype involvement; in Hook EB, Porter IH (eds): Population Cytogenetics. New York State Department of Health, Birth Defects Institute Symposium. New York, Academic Press, 1975, pp 63-79.

3 Hassold T, Chiu D: Maternal agespecific rates of numerical chromosome abnormalities with special reference to trisomy. Hum Genet 1985; 70:11-17.

4 Fisher JM, Harvey JF, Morton NE, Jacobs PA: Trisomy 18: Studies of the parent and cell division of origin and the effects of aberrant recombination on nondisjunction. Am J Hum Genet 1995;56:669-675.

5 Ramesh KH, Verma RS: Parental origin of the extra chromosome 18 in Edwards syndrome. Ann Génét 1996;39:110-112.
6 Robinson A, de la Chapelle A: Sex chromosome abnormalities; in Emery and Rimoin's Principles and Practice of Medical Genetics, ed 3. New York, Churchill Livingstone, 1996, pp 981-986.

7 Robinson A, Bender BG, Linden MG: Summary of clinical findings in children and young adults with sex chromosome anomalies. Birth Defects Original Article Ser 1990; 26:225-228.

8 Haylock J, Fitzgerald M, Danks D, Dennett X: Two cases of the 18-trisomy syndrome, one in combination with an XXY karyotype. Hum Chromos Newslett 1963;9:15-16.

9 Zellweger H, Abbo G: Double trisomy and double trisomic mosaicism. Am J Dis Child 1967;113:329-337.

10 Tsukahara M, Fukuda M, Furukawa S: Double trisomy $(48, \mathrm{XXX},+18)$. Am J Med Genet 1994;52:244.

11 Bach C, Toublanc JE, Gautier M: A case of double aneuploidy: Trisomy 18 and XXY (French). Ann Génét 1973;16:61-66.

12 Cohen MM, Bumbalo TS: Double aneuploidy: Trisomy 18 and Klinefelter syndrome. Am J Dis Child 1967;113:483-486.

13 Nielsen J, Venter M, Holm V, Askjoer AS, Reske-Nielsen E, Zizka J: Klinefelter's syndrome and trisomy 18 in a newborn boy. Clin Genet 1978;13:259-264.

14 Henchman DC, Grey J, Campbell JB, Nance S: Klinefelter's syndrome with mosaicism trisomy-18. Aust Paediatr J 1970;6:142-145.
15 Kotzot D, Bundscherer G, Bernasconi F, Brecevic L, Lurie IW, Basaran S, Baccicchetti C, Holler A, Castellan C, Braun-Quentin S, Pfeiffer RA, Schinzel A: Isochromosome $18 \mathrm{p}$ results from maternal meiosis 11 nondisjunction. Eur J Hum Genet 1996;4:168-174.

16 Hulten MA: The origin of aneuploidy: Bivalent instability and the maternal age effect in trisomy 21 Down syndrome. Am J Med Genet 1990 (suppl 7):160-161.

17 Alfi OS, Chang R, Azen SP: Evidence for genetic control of nondisjunction in man. Am J Hum Genet 1980;32:477-483.

18 Hassold TJ, Sherman SL, Pettay D, Page DC, Jacobs PA: XY chromosome nondisjunction in man is associated with diminished recombination in the pseudoautosomal region. Am J Hum Genet 1991;49:253260.

19 Zaragoza MV, Jacobs PA, James RS, Rogan P, Sherman S, Hassold $\mathrm{T}$ : Nondisjunction of human acrocentric chromosomes: Studies of 432 trisomic fetuses and liveborns. Hum Genet 1994;94:411-417.

20 Park VM, Bravo RR, Shulman LP: Double non-disjunction in maternal meiosis II giving rise to a fetus with 48,XXX,+21. J Med Genet 1995; $32: 650-653$. 